\title{
Flora Malesiana and the Flora of Nepal: floristic links and the potential for collaboration
}

\author{
C.A. Pendry ${ }^{1}$, M.F. Watson ${ }^{1}$
}

Key words

Malesia

Nepal

\begin{abstract}
The degree of overlap between the Malesian and Nepalese floras was analyzed by comparison of the distributions of twenty plant families revised for Flora Malesiana. Despite their geographic separation in some plant families there is significant overlap between the two areas at both the generic and specific levels. In seven of these families at least $40 \%$ of Nepalese species were also found in Malesia. In some families with temperate distributions up to $29 \%$ of Malesian species and all Malesian genera are also found in Nepal. It is suggested that a coordinated approach to the production of accounts of such families would improve the rate of production of accounts and would greatly facilitate knowledge transfer and help to build scientific networks and expertise in Nepal.
\end{abstract}

Published on 30 October 2009

\section{INTRODUCTION}

Over-exploitation of natural resources, degradation of habitats and the effects of climate change are all having severe impacts on the earth's biota. It is widely accepted that we are facing a biodiversity crisis, with massive rates of anthropogenic species loss (Pimm et al. 1995). Taxonomy plays a crucial role in the effective conservation and management of biodiversity in the face of this threat, but it is generally acknowledged that there are insufficient taxonomists and taxonomic resources to meet these needs, the so-called 'taxonomic impediment'. The taxonomic impediment is most pronounced in developing countries, many of which are facing the greatest disruption to natural ecosystems and thus have the greatest threats to their biodiversity. There is therefore a pressing need to produce the Floras which will give access to this primary information. Taxonomy is underresourced and its meagre resources are further stretched by the demands of phylogenetic studies (Wheeler 2004) and large-scale biodiversity informatics projects (Flowers 2007). Taxonomic activity has been eroded in the developed world (Landrum 2001) and rates of description of new plant species have been in decline since the beginning of the 20th century (Wheeler 2004). Under these circumstances it is vital that we make the best possible use of taxonomists and their time and ensure that there expertise is fully harnessed and passed on to future generations of researchers (Funk 2006).

Flora projects are notoriously slow to complete. This is particularly true for the large regional Floras, most of which will take many decades to complete at current rates of production (Polhill 1990), and there has been much discussion about ways to increase rates of productivity (Roos 1993, 2003). Roos (2003) identified the greatest potential for acceleration of the Flora Malesiana project as coming from within Malesia itself and noted the importance of training programmes to build the region's taxonomic capacity. Middleton (2003) discussed recent progress in the Flora of Thailand and highlighted the increasing role of Thai botanists in preparing Flora accounts due the increase in the numbers of Thai botanists who are being trained in Thai, European and Japanese herbaria. He also drew attention to the ongoing collaboration between Flora

\footnotetext{
${ }^{1}$ Royal Botanic Garden Edinburgh, 20a Inverleith Row, Edinburgh EH3 5LR, Scotland, United Kingdom.
}

Malesiana and the Flora of Thailand, $65 \%$ of whose species are also found in Malesia. Flora Malesiana is increasingly developing a collaborative approach to large families, e.g. the Sapindaceae whose 235 species were revised by 11 authors under the direction of Adema, Leenhouts and Van Welzen (Adema et al. 1994). Van Welzen is now directing activity on the Euphorbiaceae for Flora Malesiana and has jointly supervised work on the account for the Flora of Thailand. The larger and more complex genera have been completed by experienced Thai and European taxonomists whilst the smaller genera have mostly been allocated to Thai students. Production of family accounts for both Floras by the same author has proved to be an efficient way of maximizing taxonomic output, and particularly so if it includes the training and capacity building component of using junior researchers to complete smaller genera. We argue that because of the wide distributions of some Malesian plants this approach can usefully be extended to other countries even further from Malesia.

The aims of this paper are:

- to examine the degree of overlap of plant species and genera between Nepal and Malesia;

- to highlight the links between the plants of the Nepal and Malesia;

- to draw the attention of Malesian botanists to the rise in activity in the Flora of Nepal;

- to encourage cooperation between the two Flora projects to transfer expertise and accelerate the preparation of accounts.

\section{THE FLORA OF NEPAL}

\section{Nepal's physical environment and vegetation}

Nepal has been estimated to have a native flora of at least 6500 (Hara et al. 1978-1982) and possibly as many as 7000 (www.floraofnepal.org) species of flowering plants within its area of only about $148000 \mathrm{~km}^{2}$. Although most famous for its mountains, Nepal has a huge elevational range, and rises from only $60 \mathrm{~m}$ a.s.I. in the eastern Terai to the top of Mt Everest at $8848 \mathrm{~m}$. The climate is monsoonal and has a pronounced precipitation gradient along the length of the country with more rain falling in the east while in the west there are large areas

(c) 2009 Nationaal Herbarium Nederland

You are free to share - to copy, distribute and transmit the work, under the following conditions:

Attribution: $\quad$ You must attribute the work in the manner specified by the author or licensor (but not in any way that suggests that they endorse you or your use of the work).

Non-commercial:

You may nottribute the work in the manner specified

No derivative works: You may not alter, transform, or build upon this work.

For any reuse or distribution, you must make clear to others the license terms of this work, which can be found at http://creativecommons.org/licenses/by-nc-nd/3.0/legalcode. Any of the above conditions can be waived if you get permission from the copyright holder. Nothing in this license impairs or restricts the author's moral rights. 
of rain shadow in the highlands to the north of the main Himalayan ranges. Nepal possesses a great diversity of vegetation types due to the complex physical environment arising from the interaction of climate and rugged topography. In the lowlands it has tropical and subtropical forests with Indo-Malayan affinities (Stearn in Hara et al. 1978-1982), which are replaced at higher elevations by warm temperate evergreen, cool temperate deciduous forests and then coniferous forest to the tree line, above which is Rhododendron scrub and finally alpine vegetation. The latter formations have elements of the Sino-Japanese and Irano-Turranean floras, while the dry vegetation also has affinities with the Saharo-Sindian region (Takhtajan 1986).

\section{Plant collecting in Nepal}

Nepal was largely closed to foreigners until the middle of the 20 th century, so only limited collections were made before then. The botanical exploration of Nepal dates back to 1802 when the Scottish-born surgeon Dr Francis Buchanan-Hamilton spent a year in Kathmandu on a British East India Company diplomatic mission. Although he was restricted to the Kathmandu Valley he collected numerous plants there, many of which were new to science. The second major figure in Nepalese botany was Nathaniel Wallich, who arrived in Kathmandu in 1820 and also spent a year within the valley. His collections were more extensive than Buchanan-Hamilton's and furthermore he was able to obtain specimens from outside the Kathmandu Valley from Nepalis travelling to sacred sites in the Himalayas. Prior to 1949 , when improved access was granted to foreigners, the main collector in Nepal was Lal Dhwoj (died 1931) though Joseph Hooker also briefly visited eastern Nepal in 1848. In the second half of the 20th century Nepal was the destination for a series of expeditions from the Natural History Museum, London (BM), most notably those of Adam Stainton and Oleg Polunin and from the University of Tokyo under the leadership of Hiroshi Hara and latterly Hideaki Ohba. Many thousands of herbarium specimens were collected on these expeditions, and the UK and Japan hold the best collections of Nepalese material outside the country. The Nepal Government established a National Herbarium (KATH) in 1960, and it now has over 150000 specimens (HMGN/MFSC 2002).

Stearn (in Hara et al. 1978-1982) estimated that there was then a total of about 100000 collections from Nepal, and it is likely that efforts since then have roughly doubled this total, giving a collecting density of about 0.7 collections per $\mathrm{km}^{2}$. Comparison with a country like the UK which has a well-collected flora indicates just how poorly-collected Nepal is. The UK has a collecting density of 17.2 specimens per $\mathrm{km}^{2}$ (Parnell 2000), and the difference between the two is further accentuated by the relative sizes of the two floras; the UK having only c. 1500 native species compared with Nepal's estimated 7000 species. The pressing need for an ongoing collecting programme in Nepal is highlighted by recent collecting trips to Sagarmatha (Everest) and Chitwan National Parks which were undertaken during the recent Darwin Initiative Project (see below). Field work was restricted to these areas because of the prevailing security situation, and although these areas are among the best collected in Nepal outside the Kathmandu Valley, 37 new records for Nepal were collected including six new genera (Watson et al. 2007). It is significant that the rate of collection of new records was highest in the trip to Chitwan and the surrounding areas, where novelties were collected at the rate of $3 \%$ of all specimens (Pendry et al. in press). This figure is similar to the value reported by Adhikari (2002) for a study in the western Terai which found 12 new records were among the 226 species collected. The lowlands of the Terai are the least well-collected areas of Nepal and with their Indo-Malayan affinities the areas with the greatest overlap with Malesia.
Future collecting efforts here are likely to reinforce those links, and recent improvements in the political situation in outlying parts of the country now make this work possible.

\section{Publications on the flora of Nepal}

The first account of the plants of Nepal was David Don's Prodromus Florae Nepalensis (Don 1825) which included almost 700 species. It was based on Buchanan-Hamilton's collections with a few references to Nathaniel Wallich's early collections, though these early plants were actually collected by Gardner, the British Resident (ambassador) in Kathmandu (Fraser-Jenkins 2005). Don's Prodromus was the first publication of many Asian species, predating important works such as Hooker's Flora of British India (Hooker 1875-1897) and De Candolle's Prodromus (De Candolle \& De Candolle 1824-1873), and his names therefore take priority. However Don's work was subsequently overlooked because of professional rivalries, with the result that many Asian plants became known by later synonyms.

Wallich's prodigious efforts were recorded in his Tentamen Flora Nepalensis (Wallich 1824-1826) and Plantae Asiaticae Rariores (Wallich 1829-1832). His Numerical List of Dried Specimens of Plants (1828-1849) records the 9148 numbers representing 226000 duplicates which he distributed throughout Europe (Fraser-Jenkins 2005) and is commonly known as Wallich's Catalogue. The Catalogue was handwritten and lacks descriptions with the result that the names therein are nomina nuda and are validly published only when described in other works, such as the Flora of British India and De Candolle's Prodromus.

An Enumeration of the Flowering Plants of Nepal (Hara et al. 1978-1982) was the product of the research and collecting programmes of the Natural History Museum, London (BM) and Tokyo University ( $\mathrm{TI})$. It was a monumental effort including information on the synonymy and distribution of c. 5000 species of seed plants with keys for some genera, and continues to be an excellent resource for floristic studies. From 1997 to 2000 a UK Government funded Darwin Initiative Project based at the Natural History Museum databased information in the Enumeration and incorporated changes and additions to the flora since 1982. This work was published as the Annotated Checklist of the Flowering Plants of Nepal (Press et al. 2000) and the database is now queriable over the internet (www. efloras.org). Since 1995 the Department of Plant Resources (DPR) has been publishing family revisions as Fascicles of the Flora of Nepal primarily based on the collections at KATH, and they have also produced a country-wide checklist, the Flowering Plants of Nepal (Phanerogams) (Bista et al. 2001).

\section{The Flora of Nepal project}

The need for a comprehensive Flora of Nepal has long been recognised by the Government of Nepal in its five year plans, and it is highlighted as a priority project in the 2002 National Biodiversity strategy (HMGN/MFSC 2002). The international Flora of Nepal Project is the result of a meeting held in Edinburgh in 2002 between the Royal Botanic Garden Edinburgh (RBGE), the Royal Nepal Academy of Science and Technology (RONAST, now NAST), Tribhuvan University Central Department of Botany (TU-CDB), DPR, the University of Tokyo (TI) and the Natural History Museum (BM). It was decided that RBGE should coordinate the production of the Flora, with DPR, TI and TU-CDB supplying one editor each. The Flora will be published in 10 volumes, each of c. 700 species and will follow the same modified Englerian family order as in the Flora of China and the Flora of Bhutan. The first volume to be published will be Volume 3 (Magnoliaceae-Rosaceae) and it is anticipated that publication will be in early 2010 with the final 
volume appearing within 15 years. Further details can be found at www.floraofnepal.org.

The specimen, literature and taxonomic data underlying the Flora are managed by the Padme database which is being developed at RBGE. As accounts are completed they will be accessible over the internet, as will much additional information such as distribution data and images which can not be included in the published volumes.

The Nepalese institutions identified an urgent need for human and institutional capacity building, and an RBGE-based Darwin project from 2003 to 2006 addressed these needs by training 18 Nepalese botanists in flora writing skills, plant collecting techniques and herbarium management and by improving the infrastructure at RONAST, KATH and TUCH (Tribhuvan University). All Darwin scholars contributed accounts for the Flora of Nepal, several of which will appear in Volume 3.

\section{METHODS}

Twenty families monographed in Flora Malesiana were selected to cover a wide range of growth forms and phylogenetic diversity and including families considered to be primarily tropical and primarily temperate. The largest family examined was the Moraceae, with a total of 441 species in Malesia and Nepal, and the smallest was the Taxaceae with a total of three species in both areas. Information on the Nepalese distributions of the species and genera in these families was obtained from An Enumeration of the Flowering Plants of Nepal (Hara et al. 1978-1982), the Annotated Checklist of the Flowering Plants of Nepal (Press et al. 2000) and the online version of the Annotated Checklist (http://www.efloras.org/). Species and genera were assigned to three categories; Flora Malesiana only, Common (to both areas) and Flora of Nepal only. Where a species was represented by different subspecies or varieties in the two areas it was still treated as a single species present in both areas. In the occasional instance of cases of cultivated species being included in Flora Malesiana, these were treated in the same way as wild and naturalised species.

\section{RESULTS}

At the level of generic diversity six families (Boraginaceae, Caryophyllaceae, Cruciferae, Rosaceae, Papaveraceae and Cupressaceae) have a greater diversity in Nepal and can be considered to be temperate families (Fig. 1), while twelve families are mainly tropical and two (Daphniphyllaceae and Taxaceae) are represented by a single genus found in both regions. The twelve tropical families all had considerable overlap across the two regions at the generic level, and in ten of them all of the genera found in Nepal were also found in Malesia. In all but one of the temperate families at least $50 \%$ of the genera in Malesia were found in Nepal, and in the Cruciferae all the Malesian genera were also recorded in Nepal. The Cupressaceae was the only family which had no genera in common between the two regions.

Unsurprisingly, the degree of overlap was lower at the species level (Fig. 2). In two small families (Hammamelidaceae and Podocarpaceae) all Nepalese species were found in Malesia, while for a further five families significant proportions of the species in Nepal were also found in Malesia (Moraceae (68 \%), Polygalaceae (67\%), Capparaceae (67\%), Viscaceae (50\%), Loranthaceae (46\%)). The greatest number of such species in a single family was in the Moraceae, in which 30 Nepalese species were included in Flora Malesiana. In five families no Nepalese species at all were found in Malesia. The proportions of Malesian species represented in Nepal were much lower,

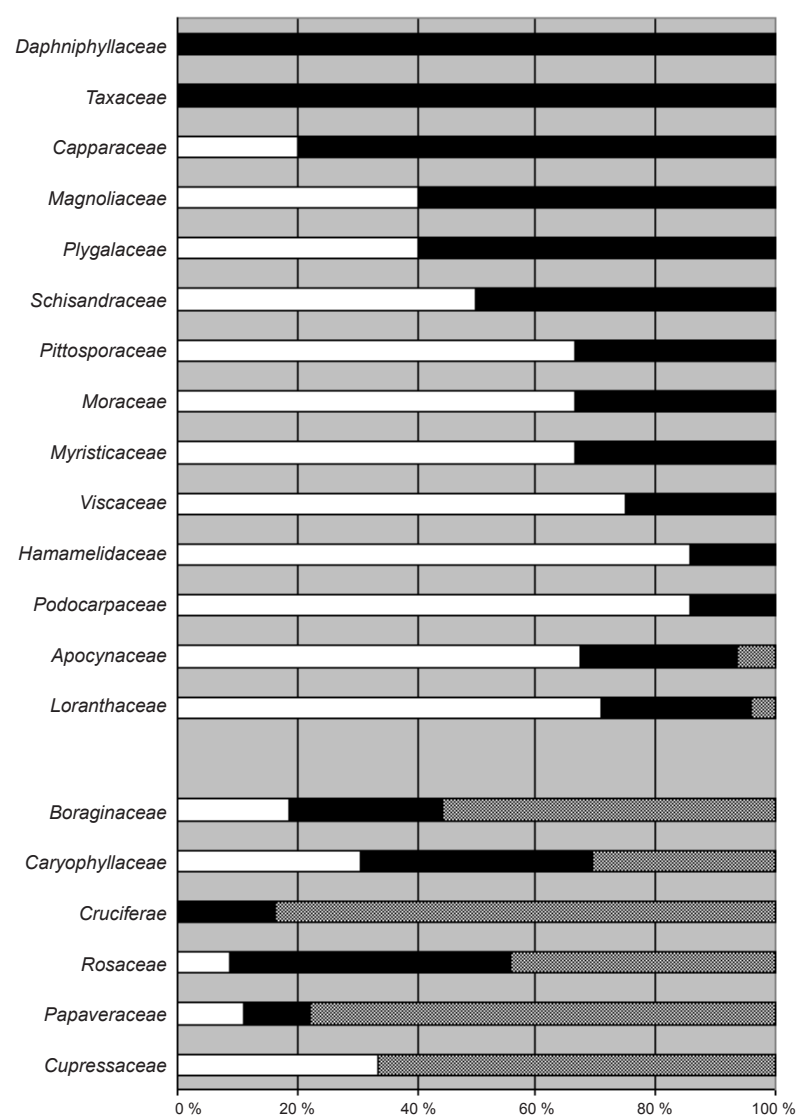

Fig. 1 The total number of genera found in Nepal and Malesia and the proportions of the genera found only in Malesia or only in Nepal or common to both areas.

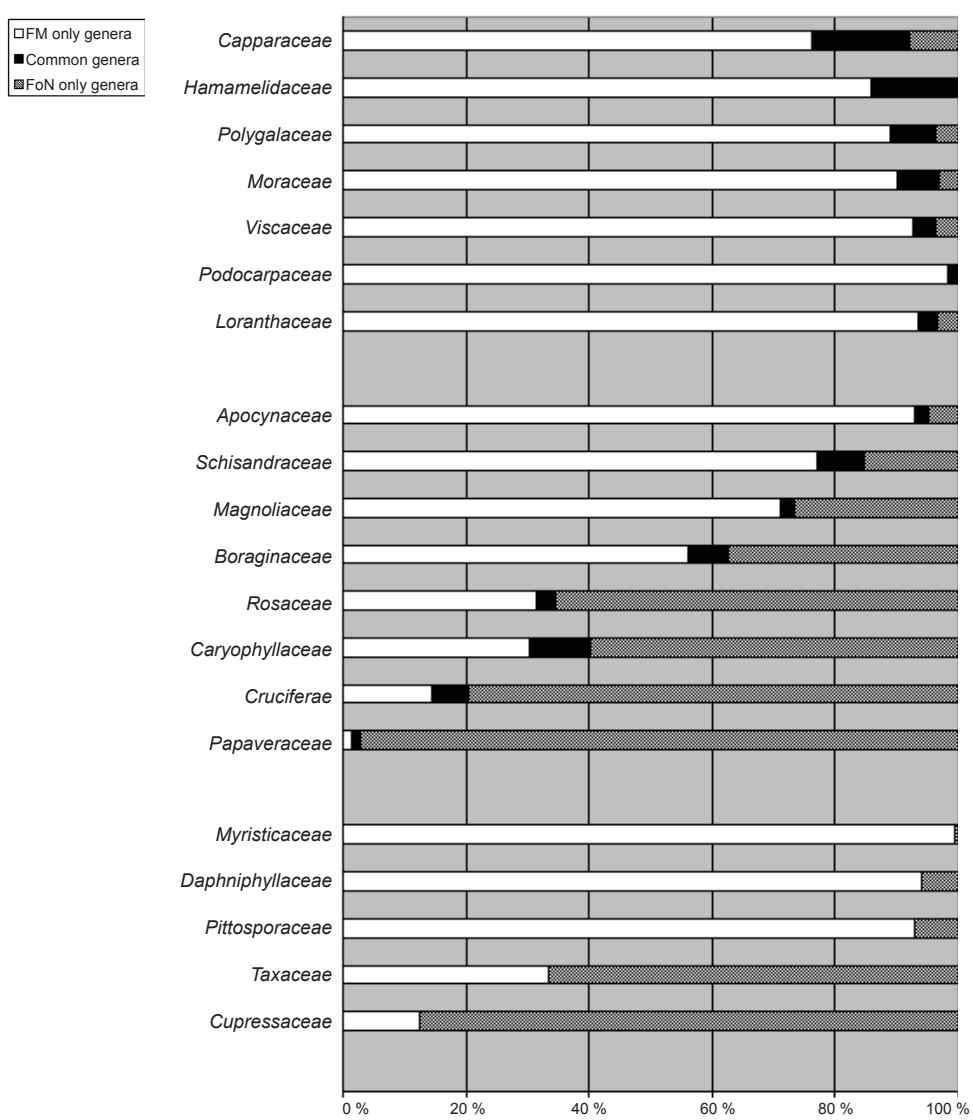

Fig. 2 The total number of species found in Nepal and Malesia and the proportions of the species found only in Malesia or only in Nepal or common to both areas. 
even for the temperate families, and the highest proportion was found in the Cruciferae in which $29 \%$ of the Malesian species (7 species) were found in Nepal, followed by the Caryophyllaceae in which $24 \%$ of the Malesian species (11 species) were found in Nepal.

\section{DISCUSSION}

It has long been recognised that in an ideal world monographic revisions would underlie Flora accounts (Davis \& Heywood 1963), resolving nomenclatural issues and clarifying species delimitations. However, this is rarely the case in the real world. Since support for large scale monographic projects is limited only small numbers of monographs are available, and a pragmatic approach to completing Flora projects should be followed with adjacent Floras coordinating their efforts to avoid replication of effort and maximizing taxonomic outputs.

Although Nepal is separated from Malesia by $3000 \mathrm{~km}$ and lies several degrees to the north of the tropics, there are many genera and some species which grow in both areas. For some families there are significant overlaps between the plants of Malesia and Nepal, not just at the generic but also at the specific level. The large numbers of Nepalese species of the Capparaceae, Moraceae and Polygalaceae with Malesian distributions show that Flora of Nepal accounts could rapidly be prepared following completion of accounts for Flora Malesiana. This has clear implications for the sharing of expertise and reducing the duplication of effort in the preparation of accounts for the two Floras. The wide distributions seen in these families is by no means universal, as there are plenty of other cases where there are very low proportions or no Nepalese species found in Malesia. It is notable that families like the Myristicaceae and Magnoliaceae have almost no overlap at the species level, and this is not unexpected as these are large-seeded forest trees which are likely to be relatively poor dispersers and slow colonisers and thus tend to have limited ranges. We therefore suggest that whilst preparing accounts for Flora Malesiana it may be profitable to check for the Nepalese distributions of the species using the Annotated Checklist of the Flowering Plants of Nepal (www.efloras.org) and if it contains significant numbers of Malesian species set up a collaboration via the Editors of the Flora of Nepal (www.floraofnepal.org). Roos (2003) identified the benefits accruing to Malesian botanists working in collaboration with external experts, and this effect would be even more pronounced for botanists in Nepal where scientific work is even less well resourced and for whom external collaborations would be even more beneficial.

Nepalese botanists could benefit hugely by joining existing networks and working with the specialists who are currently most active. This could be particularly important in ensuring that modern generic concepts are followed and species concepts are consistent across treatments. The case for even wider collaboration across eastern Asia is demonstrated by comparing the distribution of the Polygalaceae in Flora Malesiana (Van der Meijden 1988), the Flora of Thailand (Pendry 2001), the Flore du Cambodge, du Laos et du Vietnam (Pendry in press) and the Flora of Nepal (Pendry in prep.). Nepal has twelve species of Polygalaceae in three genera, all of which are found in Malesia. Of the twelve Nepalese species, eight of them are found in Malesia, eight of them in Thailand and nine in Indochina. However, eleven of them are found in at least one of these areas, making it a very simple task to complete the Flora of Nepal account based on the information collated in the preparation of the accounts in the other Floras.

A further reason for developing collaborations with the Flora of Nepal project lies in the importance of some of the 19th century collections of Buchanan-Hamilton and Wallich. These early collections are often the types of the earliest names for plants with much wider Asian distributions, and often Nepalese material and literature will have to be consulted during the research for a Flora Malesiana account.

Middleton (2003) noted that while immense benefits would come from Flora Malesiana authors contributing to the Flora of Thailand because $65 \%$ of Thai species are found in Malesia the reverse would not be the case because of the relative sizes of the Floras, with only a very small proportion of Malesian species having a Thai distribution species. However, it is important to consider each family on its own merits, and it should be remembered that temperate families may have very limited tropical distributions and for them significant proportions of the Malesian species may have extra-Malesian distributions or have close relatives from those regions. For instance, all the Malesian genera of Cruciferae and almost a third of the Malesian species are found in Nepal. In these cases it might well be appropriate for the author of the Flora of Nepal account to assist with the production of the Flora Malesiana account.

\section{CONCLUSIONS}

For some plant families there are significant overlaps between Nepal and Malesia at the generic or even specific level. In certain cases a coordinated approach to the generation of Flora accounts could improve the rate of production of accounts for both Flora projects. In some families with a primarily tropical distribution production of the Flora of Nepal account could be accomplished fairly rapidly after completion of the Flora Malesiana account as significant numbers of the Nepalese species would already have been treated. Conversely for some more temperate families experience gained in preparing the Nepalese account could be used to assist in the Flora Malesiana account. Such a programme could significantly strengthen existing capacity building activities in Nepal.

\section{REFERENCES}

Adema F, Leenhouts PW, Van Welzen PC. 1994. Sapindaceae. Flora Malesiana, Ser. I, Vol. 11: 419-768.

Adhikari, B. 2002. Contribution to the Flora of Terai-Siwalik of Western Nepal. Unpublished MSc thesis, Tribhuvan University, Kathmandu.

Bista MS, Adhikari MK, Rajbhandari K. 2001. Flowering plants of Nepal (Phanerogams). Bulletin of the Department of Plant Resources 18: 1-399.

Davis PH, Heywood VH. 1963. Principles of Angiosperm taxonomy. Van Nostrand, Princeton, N.J.

De Candolle A-P, De Candolle A. 1824-1873. Prodromus Systematis Naturalis Regni Vegetabilis, Treuttel, Wurtz (later Masson), Paris, Strasbourg, London.

Don D. 1825. Prodromus Florae Nepalensis. London.

Flowers RW. 2007. Taxonomy's unexamined impediment. The Systematist 28: 3-7.

Fraser-Jenkins CR. 2005. The first botanical collectors in Nepal - The fern collections of Hamilton, Gardner and Wallich - lost herbaria, a lost botanist, lost letters and lost books somewhat rediscovered. Bishen Singh Mahendra Pal Singh, Dehra Dun, India.

Funk VA. 2006. Floras: a model for biodiversity studies or a thing of the past? Taxon 55: 581-588.

Hara H, Stearn WT, Williams LHJ. 1978-1982. An enumeration of the flowering plants of Nepal. British Museum (Natural History). London.

HMGN/MFSC. 2002. Nepal biodiversity strategy.

Hooker JD. 1875-1897. Flora of British India, Vols 1-8. Reeve, London.

Landrum L. 2001. What has happened to descriptive systematics? What would make it thrive? Systematic Botany 26: 438-442.

Middleton DJ. 2003. Progress on the Flora of Thailand. Telopea 10: 33-42. Parnell JAN. 2000. The conservation of biodiversity: Aspects of Ireland's role in the study of tropical plant diversity with particular reference to the study of the Flora of Thailand and Syzygium. In: Rushton BS (ed), Biodiversity: The Irish dimension: 205-216. Royal Irish Academy, Dublin.

Pendry CA. 2001. Polygalaceae. Flora of Thailand 7: 498-538. 
Pendry CA. In press. Polygalaceae. Flore de Cambodge, du Laos et du Viêtnam. Muséum national d'Histoire naturelle, Paris.

Pendry CA, Watson MF, Shrestha KK, Rajbhandari KR Building. In press. Capacity for plant biodiversity, inventory and conservation in Nepal: Activities of the recent Darwin Initiative Project in Nepal. Newsletter of Himalayan Botany.

Pimm SL, Russell GJ, Gittleman JL, Brooks TM. 1995. The future of biodiversity. Science 269 (5222): 347-350.

Polhill RM. 1990. Production rates of major regional floras. Flora Malesiana Bulletin, Special Vol. 1: 11-20.

Press JR, Shrestha K, Sutton DA. 2000. Annotated checklist of the flowering plants of Nepal. The Natural History Museum, London.

Roos MC. 1993. State of affairs regarding Flora Malesiana: progress in revision work and publication schedule. Flora Malesiana Bulletin 11: 133-142.

Roos MC. 2003. Flora Malesiana 1991-2001. What has been achieved: revitalisation, momentum? What next? Telopea 10: 1-10.

Takhtajan A. 1986. Floristic regions of the world. University of California Press, Berkeley.
Van der Meijden R. 1988. Polygalaceae. Flora Malesiana, Ser. I, Vol. 10: 455539.

Wallich N. 1824-1826. Tentamen Florae Napalensis Illustratae, 1, 2. Calcutta, Serampore.

Wallich N 1828-1849. A numerical list of dried specimens of plants in the East India Company's Museum, collected under the superintendence of Dr. Wallich of the Company's Botanic Garden at Calcutta: 1-253 (nos. 1-9148). London and Hereford (lithographed by N. Wallich and G. Bentham).

Wallich N. 1829, 1830, 1832. Plantae Asiaticae Rariores, Vols. 1-3. London.

Watson MF, Blackmore S, Bajracharya D. 2007. Building capacity for plant biodiversity, inventory and conservation in Nepal. Darwin Project Final Report, Department of Environment Fisheries and Rural Affairs, UK Government.

Wheeler QD. 2004. Taxonomic triage and the poverty of phylogeny. Philosophical Transactions of the Royal Society of London, B, 359: 571-583. 